\title{
Clinical, electrocardiographic and echocardiographic abnormalities in Latin American migrants with newly diagnosed Chagas disease 2005-2009, Barcelona, Spain
}

L Valerio (lvalerio.bnm.ics@gencat.sat) ${ }^{1}$, S Roure $^{1}$, M Sabrià $^{2}$, X Balanzó ${ }^{3}$, X Vallès $^{2}$, L Serés ${ }^{2}$

1. North Metropolitan International Health Unit, Institut Català de la Salut, Universitat Autònoma de Barcelona, Barcelona, Spain

2. Hospital Universitari Germans Trias i Pujol, Institut Català de la Salut, Universitat Autònoma de Barcelona, Barcelona, Spain

3. Hospital de Mataró, Mataró, Spain

Valerio L, Roure S, Sabrià M, Balanzó X, Vallès X, Serés L. Clinical, electrocardiographic and echocardiographic abnormalities in Latin American migrants with

Following Latin American migration, Chagas disease has inevitably appeared in non-endemic countries in Europe and elsewhere. New policies are necessary to prevent transmission in those countries but the long, often undetected chronic period of the early stages of the disease also renders epidemiological studies important. The main objective of our study was to determine the presence of clinical, electrocardiogram (ECG) and echocardiographic abnormalities in a population of Latin American migrants infected with Trypanosoma cruzi at the moment of diagnosis. We performed a hospital-based observational study of 100 adult patients with newly diagnosed Chagas infection between January 2005 and December 2009. Thirtyseven patients were classified within the Brazilian Consensus on Chagas cardiomyopathy early cardiac stages (A or B1) and 49 presented pathological findings (stage $B_{2}$ ) according to the Panamerican Health Organization Classification. Overall, 49 patients showed ECG and/or echocardiographic alterations. The presence of ECG and ecocardiographic alterations were significantly associated $(p=0.038)$. The most frequent ECG and echocardiographic findings were right bundle branch block (12 cases) and impaired left ventricular wall relaxation (24 cases), respectively. In conclusion, ECG and echocardiographic alterations coherent with Chagas cardiomyopathy were found in a large proportion of newly diagnosed Latin American migrants infected with $T$. cruzi. In the mid-term, Chagas disease might become an important cause of chronic cadiomyopathy in our attendance area.

\section{Introduction}

Chagas disease is a zoonosis caused by the parasite Trypanosoma cruzi, a flagellated protozoa mainly transmitted to humans by the faeces of blood-sucking triatomine bugs (Triatoma infestans and others). A hundred years from its description, Chagas disease remains a neglected tropical disease and is as such recognised by the World Health Organization [1]. Until the late twentieth century, Chagas had a geographical distribution that was confined to that of its vector, namely in Central and South America. Today, the disease is no longer confined to Central and South America. Non-endemic countries in Europe and elsewhere have seen the emergence of Chagas disease following migration of chronically infected individuals from endemic areas. In Europe, for example, there are an estimated 2,300,000 Latin American migrants, both documented or undocumented $[2,3]$ and non-endemic countries need to consider implementing preventive policies concerning blood transfusion, organ transplantation and vertical transmission $[4,5]$.

Acute Chagas disease manifests clinically with fever and lyphadenopathy, unspecific general malaise and is self-limiting. It is followed by a long asymptomatic period of latency (or chronic disease) characterised by the presence of antibodies against Trypanosoma cruzi. In this stage, clinical examination of the chest, oesophagus and colon may be normal, the 12-lead electrocardiogram (ECG) can show no irregularities or minor alterations. After decades of undetected, asymptomatic disease, over $40 \%$ of infected individuals develop clinical symptoms reflecting the tissue damage. They usually involve the heart or digestive tract. The clinical outcome of the chronic phase of Chagas disease ranges from the absence of sings and symptoms to sudden premature deaths due to silent severe cardiomyopathy. Classically it is considered that up to a $30 \%$ of those infected will develop cardiac symptoms or ECG alterations within 10-30 years after the initial infection [6].

Although the pathogenesis of Chagas is not completely understood, a growing consensus points to a combination of direct tissue effects of the parasite with an immunologic response that may paradoxically increase 
the tissue inflammation and thus over time lead to fibrosis [7]. Such low-intensity inflammation causes the specific Chagas cardiomyopathy and sooner or later affects the conduction system. This affection is reason for the often pathological ECG findings in Chagas patients [8].

Chagas cardiomyopathy marks the prognosis of the disease. It results in impairment of contractile function and final dilation of all four heart chambers. Eventually, ventricular tachycardia or refractory congestive heart failure threaten the lives of those affected [9].

Spain has become the main European destination of Latin migration in recent decades [10]. We undertook a hospital-based descriptive study to determine the presence of cardiac (clinical, ECG and echocardiographic) alterations in of a population of infected Latin American migrants at the moment of the diagnosis as well as to estimate their clinical and functional cardiac staging.

\section{Methods}

Between January 2005 and December 2009, we studied all consecutive adult patients newly diagnosed with Chagas infection at the Unitat de Salut Internacional Metropolitana Nord. The Unitat de Salut is a referral unit shared by the Primary Care Service and the tertiary care Hospital Universitari Germans Trias i Pujol. Both are located in the Barcelona Metropolitan Area, Spain; they serve a population of over two million people of which approximately $6 \%$ are Latin American migrants. The unit belongs to the Institut Català de la Salut, the main public health provider in Catalonia and, therefore, the medical visits were free of charge. The majority of patients were referred by family practitioners as foreseen in the protocol of the Chagas screening program for populations at risk (i.e. Latin American pregnant women, Bolivian natives, other Latin American migrants with any risk factor for Chagas disease) at primary care level in Catalonia [11].

Exclusion criteria for the study were: (i) documented previous diagnose of Chagas infection or antichagasic treatment, (ii) age less than 15 years, (iii) presence of hypertension, diabetes, coronary artery disease or other concurrent diseases associated with cardiomyopathy and, (iv) pregnancy.

Individuals were considered as Chagas cases when two commercialised enzyme-linked immuno sorbent assay (ELISA)-based serological tests against crude and recombinant $T$. cruzi antigens, were positive. In case of discrepant results, a third test, based on indirect immunoflourescence (IIF) was performed.

All newly-diagnosed Chagas patients underwent a clinical evaluation, including full medical history, physical examination, ECG with 30 seconds DII strip and a twodimensional and Doppler echocardiography.

The following variables were assessed: age, sex, country of origin and having lived in rural environment (yes/ no), previous adobe housing (yes/no) self-reported family history of Chagas infection (yes/no), mother with Chagas infection (yes/no), cardiac symptoms, ECG alterations, echocardiographic abnormalities, debut as acute cardiac event (i.e. tachyarrythmia, cardiac syncope, pulmonary or systemic tromboembolism and acute heart failure) and Chagas cardiomyopathy staging.

The variable "cardiac symptoms", assessed as a dichotomy variable (yes/no) included at least one of the following features: antecedents of chest pain, palpitations, syncope, pulmonary thromboembolism, stroke and symptoms of heart failure such as oedema of the lower legs or dyspnoea on exertion.

The ECG alterations assessed were: sinus bradycardia, right bundle branch block, left anterior fascicular block, left bundle branch block, posterior fascicular block, atrial fibrillation, any degree of atrioventricular block, ventricular extrasystoles and $Q$ wave or diffuse ST-T changes presence.

FIGURE 1

Classification schemes to grade Chagas cardiomyopathy

Brazilian Consensus Classification [12]

A: Abnormal ECG findings. Normal echocardiogram. No signs of CHF.

B1: Abnormal ECG findings. Abnormal echocardiogram with LVEF> 45\%. No signs of CHF.

B2: Abnormal ECG findings. Abnormal echocardiogram with LVEF< $45 \%$. No signs of CHF.

C: Abnormal ECG findings. Abnormal echocardiogram. Compensated CHF.

D: Abnormal ECG findings. Abnormal echocardiogram. Refractory CHF.

Panamerican Health Organization Consensus [13]

A. Acute Chagas disease

A.1. Symptomatic disease

A.2. Asymptomatic disease

B. Chronic Chagas disease

B.1. Absence of pathological findings

B.2. Presence of pathological findings

CHF: congestive heart failure; ECG: electrocardiogram; LVEF: left ventricular ejection fraction. 
The echocardiographic alterations assessed were: left ventricular wall dysfunction, ventricular aneurysm (apical or other), low ejection fraction (if ${ }_{50} 0 \%$ ) and valve disease attributable to Chagas endocardial fibrosis.

For the Chagas cardiomyopathy staging we used the Brazilian Consensus [12] and the recent Panamerican Health Organization Classification of Chagas cardiomyopathy [13] (Figure 1). The Brazilian Consensus classification categorises "left ventricular low ejection fraction" according to data based on echocardiographic outcomes (Figure 1).

The relative frequency of the variables and their association with socio-demographic (age, sex, family history and mother with Chagas infection) or setting characteristics (having lived in rural environment, previous adobe housing) were analysed using SPSS 12.0 software (SPSS Inc, Chicago, IL). The chi-square test was applied to compare qualitative variables.

We performed a multivariate logistic regression. Depending variables were to have cardiac symptoms, and to present ECG or echocardiographic alterations; independent variables were age, sex, previous adobe housing and reported family or mother with $T$. cruzi infection.

Results were presented in terms of crude and adjusted (by age, sex and rural environment) odds ratios (OR) and $95 \%$ confidence intervals $(95 \% \mathrm{Cl})$. A tendency test compared ECG or echocardiographic alterations' presence with the Brazilian Consensus staging of cardiomyopathy. The $p$ value was set at 0.05 for statistical significance.

\section{Results}

During the study period, 116 Latin American immigrants were newly-diagnosed with $T$. cruzi infection. Patients were excluded because of previous diagnosis or treatment of Chagas infection (8), age under 15 years (2), concurrent cardiovascular diseases (2), pregnancy (4). One hundred patients remained in the study. The median age of the patients was $38.2(S D=10.2)$ years, 65 were female and the vast majority were from Bolivia. Socio-demographic and clinical characteristics are shown in Table 1.

Overall, 41 patients had some ECG alteration at the moment of the diagnosis. The most common alteration was a single right bundle branch block (12 cases) which, combined with any other alteration, accounted for 18 of 41 abnormal ECG findings. Echocardiographic changes were seen in 31 patients, and allowed the diagnosis of Chagas cardiomyopathy in eight individuals with a normal ECG (Table 2). The presence of ECG and echocardiogram alterations showed a significant association $(p=0.038)$.

\section{TABLE 1}

Socio-demographic and clinical characteristics of newly diagnosed Chagas disease patients, hospital-based study Barcelona, Spain 2005-2009 $(n=100)$

\begin{tabular}{|c|c|}
\hline Variable & $\mathrm{N}(\%)$ \\
\hline Mean Age & $38.2(10.2)$ \\
\hline \multicolumn{2}{|l|}{ Sex } \\
\hline Male & $35(35)$ \\
\hline Female & $65(65)$ \\
\hline \multicolumn{2}{|l|}{ Country of origin } \\
\hline Bolivia & $95(95)$ \\
\hline Other Southern American countries ${ }^{1}$ & $5(5)$ \\
\hline Rural environment & $93(93)$ \\
\hline Adobe house & $91(91)$ \\
\hline Reported family history of T. cruzi infection ${ }^{2}$ & $66(67 \%)$ \\
\hline Reported mother with T. cruzi infection ${ }^{3}$ & $19(20 \%)$ \\
\hline \multicolumn{2}{|l|}{ Single ECG alterations } \\
\hline Sinus bradycardia & $7(7)$ \\
\hline Right bundle branch block & $12(12)$ \\
\hline Left anterior fascicular block & $6(6)$ \\
\hline Left bundle branch block & 0 \\
\hline Posterior fascicular block & $1(1)$ \\
\hline Atrial fibrillation & $1(1)$ \\
\hline Atrioventricular block & $3(3)$ \\
\hline Ventricular extrasystoles & 0 \\
\hline Q wave/ST-T changes & $1(1)$ \\
\hline 2 alterations & $9(9)$ \\
\hline 3 alterations & $1(1)$ \\
\hline Total ECG alterations & $41(41)$ \\
\hline \multicolumn{2}{|l|}{ Abnormal echocardiographic alterations } \\
\hline Left ventricular wall dysfunction & $24(24)$ \\
\hline Ventricular aneurysm (apical or other) & $2(2)$ \\
\hline Low ejection fraction ( $(50 \%)$ & $4(4)$ \\
\hline Valve disease i.e Mitral regurgitation| & $1(1)$ \\
\hline Total echocardiographic alterations & $31(31)$ \\
\hline Total ECG and/or echocardiogram alteration & $49(49)$ \\
\hline Debut as cardiac event & $3(3)^{4}$ \\
\hline Cardiac symptoms & $31(31)$ \\
\hline
\end{tabular}

ECG: Electrocardiogram.

Ecuador (2), Brasil (1), Uruguay (1), Venezuela (1).

Information available for $\mathrm{n}=98$ patients.

Information available for $\mathrm{n}=95$ patients.

Pulmonary tromboembolism (1), rapid atrial fibrillation (1), syncope (1).

\section{TABLE 2}

Electrocardiogram and echocardiographic findings in newly diagnosed Chagas disease patients, hospital-based study Barcelona, Spain 2005-2009 ( $\mathrm{n}=100)$

\begin{tabular}{|c|l|c|c|c|}
\multirow{3}{*}{ ECG } & \multicolumn{3}{|c|}{ Echocardiogram } & \multirow{2}{*}{ Total } \\
\cline { 2 - 4 } & & Normal & Abnormal & \\
\cline { 2 - 5 } & Normal & 51 & 8 & 59 \\
\cline { 2 - 5 } & Abnormal & 18 & 23 & 41 \\
\hline Total & 69 & 31 & 100 \\
\hline
\end{tabular}

$p=0.038$ 
No statistically significant relations were found between cardiac symptoms, ECG or echocardiographic alterations and age or sex (Table 3 ).

According to the Panamerican Health Organization Classification, none of the patients was classified as stage A, 100 were in stage $B$ and of those 51 in stage $B 1$, and 49 in stage B2. According to the Brazilian Consensus, 25 patients were in stage $A$ and 14 in stage $B$, of those 12 in stage $B 1$ and two in stage B2, none were in stage C. Overall, 37 patients were in an early stage of Chagas cardiomyopathy (stage A and $B_{1}$ ).

The tendency test comparing the Brazilian Consensus classification and the presence of ECG and echocardiographic alterations was performed. For both variables, test results were complementary. They showed a statistically significant association between higher grade in the Brazilian Consensus classification and ECG or echocardiographic alterations respectively; for ECG alterations the $p$ value was $<0.001$, the OR 11.03 (95\% Cl: 6.7-18.1) and for echocardiographic alterations p<0.001 and OR 3.4, (95\% Cl: 1.6-7.1).

\section{Discussion and conclusion}

In our study of newly diagnosed Chagas disease patients, previous adobe housing was associated with presence of ECG alterations. This may be explained by the high probability of repetitive exposure of those living in adobe houses to triatomine bites with subsequent reinfections that can trigger autoimmune reaction and greater tissue damage [14]. In contrast with the majority of Chagas epidemiological studies, the presence of reported infection in the family and mother were associated with a decreased risk of ECG abnormalities. Several articles published, although not in a conclusive way, suggest the opposite. A familial aggregation could exist among Chagas cardiomyopathy cases due to a higher number of mother-to-child transmissions by highly infectious $T$. cruzi strains or due to a longer infection period $[15,16]$. This fact could be explained by taking into account that the infected individual, usually asymptomatic and mainly with normal cardiac tests, was considered as "reference case" and a $T$. cruzi active research was done among close asymptomatic relatives. Of course, it was also carried out among patients with a beginning cardiac complication but, on the whole, family clustering tends to occur in chronic asymptomatic cases and overestimates their relationship with the asymptomatic stages of the disease. In our study, the presence of family and maternal history of Chagas infection relied on reported information from the patients; as relatives could not be serologically tested, this result should be interpreted cautiously. Overall, it likely represents a bias exemplifying the inherent shortcomings in studying a disease outside its own bio-geographic, endemic framework.

Factors consistently related in the literature to poor prognosis, such as age, male sex and multiple ECG alterations were not confirmed in our analysis. However, age is a risk factor for Chagas cardiomyopathy beyond any doubt $[17,18]$, and it should be taken into account that in our small study group only 11 individuals were over 50 years old.

\section{TABLE 3}

Cardiac symptoms, electrocardiographic and echocardiographic alterations in newly diagnosed Chagas disease patients by age, sex, housing and infections in the family, hospital-based study Barcelona, Spain 2005-2009 (n= 100)

\begin{tabular}{|c|c|c|c|c|}
\hline \multirow[b]{2}{*}{ Cardiac Symptoms } & \multicolumn{2}{|c|}{ Univariate analysis } & \multicolumn{2}{|c|}{ Multivariate analysis } \\
\hline & OR $(95 \% \mathrm{Cl})$ & $\mathrm{p}$ & OR $(95 \% \mathrm{Cl})$ & $\mathrm{p}$ \\
\hline Age & $1.01(0.9-1.1)$ & 0.7 & $1.01(0.9-1.0)$ & 0.8 \\
\hline Sex & $2.34(0.9-6.3)$ & 0.08 & $2.45(0.8-7.5)$ & 0.1 \\
\hline Adobe housing & $0.39(0.1-1.4)$ & 0.1 & $0.29(0.1-1.3)$ & 0.1 \\
\hline Reported family history of T. cruzi infection & $0.83(0.3-2.1)$ & 0.7 & $0.79(0.3-2.3)$ & 0.7 \\
\hline Reported mother with T. cruzi infection & $0.34(0.1-1.3)$ & 0.1 & $0.28(0.1-1.2)$ & 0.09 \\
\hline \multicolumn{5}{|l|}{ ECG alterations } \\
\hline Age & $0.98(0.9-1.0)$ & 0.3 & $0.98(0.9-1.0)$ & 0.3 \\
\hline Sex & $0.78(0.3-1.8)$ & 0.6 & $1.42(0.5-4.0)$ & 0.5 \\
\hline Adobe housing & $5.87(1.1-31.6)$ & 0.02 & $11.52(1.8-75.9)$ & 0.01 \\
\hline Reported family history of T. cruzi infection & $0.23(0.1-0.7)$ & 0.003 & $0.12(0.04-0.4)$ & 0.001 \\
\hline Reported mother with T. cruzi infection & $0.30(0.1-0.9)$ & 0.02 & $0.23(0.1-0.7)$ & 0.01 \\
\hline \multicolumn{5}{|l|}{ Echocardiographic alterations } \\
\hline Age & $1.05(0.9-1.1)$ & 0.2 & $1.07(0.9-1.2)$ & 0.2 \\
\hline Sex & $0.38(0.1-1.8)$ & 0.2 & $0.21(0.02-1.7)$ & 0.1 \\
\hline Adobe housing & $0.61(0.1-4.5)$ & 0.5 & $0.66(0.04-9.8)$ & 0.8 \\
\hline Reported family history of $T$. cruzi infection & $0.53(0.1-3.1)$ & 0.5 & $0.65(0.1-7.3)$ & 0.7 \\
\hline Reported mother with T. cruzi infection & $0.56(0.1-2.8)$ & 0.5 & $0.68(0.1-5.2)$ & 0.7 \\
\hline
\end{tabular}

$\mathrm{Cl}$ : confidence interval; T: Trypanosoma. 
Fourty-one of our patients showed some of ECG alterations, a far higher prevalence compared with that obtained in recent studies in other European countries such as Switzerland (11.3\% [19], France (23.6\% [20] or even Barcelona urban area (19\%) [21]. In contrast, it seems to follow a pattern similar to that described in studies carried out in endemic areas in South America: Northern Argentina (37.5\%) [22] and Bolivia (50.8\%) [23]. This may be explained by the origin of our study population. Nearly all patients came from rural highprevalence Bolivian environments, especially from Santa Cruz and Cochabamba Departments.

The prognosis of our patients is cause for concern. In one study carried out in rural Brazil, mortality over a six-year period was approximately $20 \%$ among infected persons with right bundle branch block [24]. Right bundle branch block was by far the most common ECG alteration in our sample (12 cases). Considering that the treatment given to patients, a 60-day course of benznidazol, could at best retard the progression of cardiac disease [25], close clinical follow up and early identification of complications are crucial. They are the only realistic options with benefit for patients. However, close follow up remains a challenge due to the often great instability of migrant populations in terms of employment and housing.

The predominant echocardiographic abnormalities were alterations in left ventricular wall relaxation, usually to a moderate degree, as a likely reflection of the underlying fibrosis [26]. Unlike the ECG, echocardiography is a dynamic test that requires experience. Even in specialised centres, major disparities between echocardiographic features and post-mortem lesions have been described in Chagas disease patients [27]. However, we were able to identify with echocardiography eight of cardiac abnormalities that would not have been picked up through ECG results alone. This could be due to presence of very early fibroid lesions without ECG changes in a study population that was mainly in the early stages of heart disease.

Coherently with the outcomes of other studies [28, 29], it may be reasoned that ECG and echocardiogram evaluate different aspects i.e. conduction system and structural-functional situation of the left ventricle, respectively of a specific cardiomyopathy in which left ventricular relaxation can be often identified as the earliest alteration [30]. Hence, both tests should be routinely carried out at the moment of diagnosis [31].

The Brazilian Consensus classification of Chagas cardiomyopathy proved useful in categorising the cardiac function based on ECG or echocardiogram abnormalities. As in a recent Swiss study, it was considered as a suitable tool to staging Chagas cardiomyopathy in Europe [19]. The PAHO classification, however, may give a better idea of the Chagas disease burden at public health level as it clearly divides the infected popula- tion into those with and without pathological (clinical, ECG or echocardiographic) findings.

The central limitation of our study was the lack of patients in advanced stages of Chagas cardiomyopathy. Therefore, it was not possible to estimate the association between the severity of heart disease and the presence of concrete ECG or echocardiographic findings. Besides, the absence of a Latin American-migrant control group without Chagas disease makes it impossible to determine to what extent the described cardiac alterations are attributable to Chagas disease in Latin Americans. Moreover, the study population may not be fully representative of all Latin American migrants in the European Union or other non-endemic countries due to a possible under-representation of non-Bolivian or middle class patients. Patients assessed had been "filtered" by their family doctors and, therefore, they probably do not reflect exactly the clinical situation of Latin American patients in the community.

Our study results show that clinical, ECG and echocardiographic alterations coherent with Chagas cardiomyopathy were found in a large proportion of Latin American migrants with chronic Chagas disease. The majority were in early asymptomatic stages of the disease. Given these findings and the high number of migrants from endemic areas in our attendance area, Chagas disease might become an important cause of chronic cadiomyopathy in the mid-term in our attendance area. It should be considered in every Latin American patient with unexplained ECG abnormalities, cardiac symptoms or acute cardiovascular events. Chagas disease should no longer be perceived as an exotic disease. Due to its multiorgan, particularly cardiac manifestation, we recommend to involve a multidisciplinary collaborative patient management, including primary care physicians, cardiologists and tropical-medicine experts. Every effort directed towards identifying asymptomatic infected Latin American migrants should be encouraged st

\section{References}

1. Pan American Health Organization (PAHO). Enfermedad de Chagas (Tripanosomiasis americana). [Chagas disease (American tripanosomiasis)]. PAHO. [Accessed 2 Feb 2011]. Available from: http://www.paho.org/Project.asp?SEL=TP\&LNG $=S P A \& C D=C H A G A \& P R G R P=$ resourc $\_$gen

2. Vasileva K. Statistics in focus. Citizens of European countries account for the majority of the foreign population in EU-27 in 2008. Luxembourg: Eurostat; 2009. Report No.: 94/2009. Available from: http://epp.eurostat.ec.europa.eu/cache/ITY OFFPUB/KS-SF-09-094/EN/KS-SF-09-094-EN.PDF

3. International Organization for Migration (IOM). IOM Migration Research Series No 16. Migration from Latin America to Europe: trends and policy challenges. IOM; May 2004. Available from: http://www.oas.org/atip/migration/iom\%2oreport $\% 20$ migration $\% 20$ lac\%20to\%20eu.pdf

4. Biolo A, Ribeiro AL, Clausell AN. Chagas cardiomyopathywhere do we stand after a hundred years?. Prog Cardiovasc Dis. 2010;52(4); 300-16.

5. Gascon J, Bern C, Pinazo MJ. Chagas disease in Spain, the United States and other non-endemic countries. Acta Trop. 2010;115(1-2):22-7.

6. Rassi A Jr, Rassi A, Marin-Neto N. Chagas disease. Lancet. 2010;375(9723):1388-402. 
7. Kierszenbaum F. Mechanisms of pathogenesis in Chagas disease. Acta Parasitol. 2007;52(1):1-12.

8. Marin-Neto JA, Cunha-Neto E, Maciel BC, Simoes MV. Pathogenesis of chronic Chagas heart disease. Circulation. 2007;115(9):1109-23.

9. Punukollu G, Gowda RM, Khan IA, Navarro VS, Vasavada BC. Clinical aspects of the Chagas' heart disease. Int J Cardiol. 2007;115(3):279-83.

10. Spanish Government. Ministry of Immigration and Labour. La immigración en España: permanencia y equilibrio entre comunitarios y extracomunitarios. [Immigration in Spain: permanence and balance between EU and non-EU citizens]. 22 Aug 2011. Spanish. Available from: http://www.tt.mtin.es/ periodico/inmigracion/201108/INM20110822.htm

11. Government of Catalonia. Department of Health. Protocolo de cribado y diagnóstico de la enfermedad de Chagas en mujeres latinoamericanas embarazadas y sus bebés. [Protocol for screening and diagnosis of Chagas disease in pregnant Latin American women and their babies]. Government of Catalonia.27 Jan 2010. Spanish. Available from: www.gencat. cat/salut/depsalut/html/es/dir125/chagasespanyol2010.pdf

12. Ministério da Saúde. Secretaria de Vigilância em Saúde. Consenso brasileiro em doença de chagas [Brazilian Consensus on Chagas Disease]. Rev Soc Bras Med Trop. 2005;38: Suppl3: 7-29. Portuguese.

13. Mordini OD, Mitelman J. Clasificación Enfermedad de Chagas. Consenso Internacional Buenos Aires 2010. [Chagas disease classification. International Consensus Buenos Aires 2010]. [Accessed 5 May 2011]. Spanish. Available from: http://www. fac.org.ar/1/comites/chagas/Clasificacion_Enfermedad_de_ Chagas.pdf

14. Hyland KV, Leon JS, Daniels MD, Giafis N, Woods LM, Bahk TJ, et al. Modulation of autoimmunity by treatment of an infectious disease. Infect Immun. 2007;75(7):3641-50.

15. Silva-Grecco RL, Balarin MA, Correia D, Prata A, Rodrigues V Jr. Familial analysis of seroposivity to Trypanosoma cruzi and of clinical forms of Chagas disease. Am J Trop Med Hyg. 2010;82(1):45-8.

16. Black CL, Ocaña-Mayorga S, Riner DK, Costales JA, Lascano MS, Arcos-Terán L, et al. Seroprevalence of Trypanosoma cruzi in rural Ecuador and clustering of seropositity within households. Am J Trop Med Hyg. 2009;81(6):1035-40.

17. Silva S, Gontijo ED, Amaral CF. Case-control study of factors associated with chronic Chagas heart disease in patients over 50 years of age. Mem Inst Oswaldo Cruz. 2007;102(7): 845-51.

18. Basquiera AL, Sembaj A, Aguerri AM, Omelianiuk M, Guzman S, Moreno Barral J, et al. Risk progression to chronic Chagas cardiomyopathy: influence of male sex and of parasitemia detected by polymerase chain reaction. Heart. 2003:89(10):1186-90.

19. Jackson Y, Getaz L, Wolff H, Holst M, Mauris A, Tardin $A$, et al. Prevalence, clinical staging and risk for bloodborne transmission of Chagas disease among Latin American migrants in Geneva, Switzerland. PLoS Negl Trop Dis.2010;4(2):e592.

20. Lescure FX, Paris L. Elghouzzi MH, Le Loup G, Develoux M, Touafek F, et al. [Experience of targeted screening of Chagas disease in Ile-de-France]. Bull Soc Pathol Exot. French. 2009; 102: 295-9.

21. Muñoz J, Gomez i Prat J, Gállego M, Gimeno F, Treviño B, LópezChejade 0 , et al. Clinical profile of Trypanosoma cruzi infection in a non-endemic setting: immigration and Chagas disease in Barcelona (Spain). Acta Trop. 2009;111(1): 51-5.

22. Moretti E, Castro I, Franceschi C, Basso B. Chagas disease: serological and electrocardiographic studies in Wichi and Creole communities of Misión Nueva Pompeya, Chaco, Argentina. Mem Inst Oswaldo Cruz. 2010;105(5):621-7.

23. Hidron Al, Gilman RH, Justiniano J, Blakstock AJ, LaFuente C, Selum W, et al. Chagas cardiomyopathy in the context of the chronic disease transition. PLoS Negl Trop Dis. 2010;4(5):e688.

24. Maguire HJ, Hoff R, Sherlock I, Guimarães AC, Sleigh AC, Ramos NB, et al. Cardiac morbidity and mortality due to Chaga's disease: prospective electrocardiographic study of a Brazilian community. Circulation. 1987;75(6):1140-5.

25. Viotti R, Vigliano C, Lococo B, Bertocchi G, Petti M, Alvarez $M G$, et al. Long term cardiac outcomes of treating chronic Chagas disease with benznidazol versus not treatment: a nonrandomized trial. Ann Intern Med. 2006;144(10):724-34.

26. Acquatella H. Echocardiography in Chagas heart disease. Circulation. 2007;115:1124-31.

27. Gurgel CB, Ferreira MC, Mendes CR, Coutinho E, Favoritto $P$, Carneiro F. [Apical lesions in Chaga's disease patients: an autopsy study]. Portuguese. Rev Soc Bras Med Trop. 2010;43(6):709-12.
28. Rigou DG, Gullone N, Carnevali L, De Rosa AF. Chagas asintomático. Hallazgos electrocardiograficos y ecocardiograficos. [Asymptomatic Chagas disease. Electro and echocardiographic findings]. Medicina (Buenos Aires). 2001;61(5):541-4. Spanish.

29. Combellas I, Puigbo JJ, Acquatella H, Tortoledo F, Gómez JR. Echocardiographic features of impaired left ventricular diastolic function in Chaga's disease. Br Heart J. 1985;53(3):298-309.

30. Patel AR, Lima C, Parro A, Arsenault M, Vannan MA, Pandian NG. Echocardiographic analysis of regional and global left ventricular shape in Chagas' cardiomyopathy. Am J Cardiol. 1998;82(2):197-202.

31. Viotti RJ, Vigliano C, Laucella S, Lococo B, Petti M, Bertocchi $G$, et al. Value of echocardiography for dignosis and prognosis of chronic Chagas disease without heart failure. Heart. 2004;90(6):655 